\title{
A escrita de Teresa Moure e a identidade feminina
}

\section{Teresa Moure’s Writing and Feminine Identity}

\author{
Alicia Romero López \\ Westfälische Wilhelms-Universität Münster \\ Departamento de Filoloxía Románica \\ aliciafilol@gmail.com
}

[recibido 31/10/2014, aceptado 08/02/2015]

\section{RESUMO}

Neste breve traballo amosaranse as ideas de Teresa Moure reflectidas no seu ensaio A palabra das fillas de Eva, publicado en 2005, e a evolución das mesmas na súa obra Queer-emos un mundo novo, de 2012. Tamén se exemplificará, a través da súa novela Herba Moura (2005), como a autora galega traslada os seus postulados teóricos á súa literatura.

PALABRas CHAVE: Teresa Moure, feminismo, Herba Moura, identidade feminina.

\section{RESUMEN}

En este breve trabajo se presentarán las ideas de Teresa Moure reflejadas en su ensayo A palabra das fillas de Eva, publicado en 2005, y la evolución de las mismas en su obra Queer-emos un mundo novo, de 2012. También se ejemplificará, a través de su novela Herba Moura (2005), cómo la autora gallega traslada sus planteamientos teóricos a su literatura.

PALABRAS ClaVE: Teresa Moure, feminismo, Herba Moura, identidad femenina.

\begin{abstract}
This brief study will explore how the key themes of Teresa Moure's writing are developed in the 2005 essay $A$ palabra das fillas de Eva and will chart their evolution in the 2012 publication Queer-emos un mundo novo. The investigation will also examine how the writer applies the theory of her essays to her fiction in the novel Herba Moura (2005).

KEY wORDS: Teresa Moure, feminism, Herba Moura, feminine identity.

Romero López, A. (2015): “A escrita de Teresa Moure e a identidade feminina”, Madrygal (Madr.), 18, Núm. Especial: 377-386.

SUMARIO: 1. Introdución. 2. O feminismo da diferenza e a identidade feminina: A palabra das fillas de eva e Herba moura. 2.1. Sabedoría feminina: a palabra das mulleres. 2.2. Maternidade e sexualidade en Teresa Moure. 3. Unha breve ollada a Queer-emos un mundo novo. 4. Conclusións. 5. Referencias bibliográficas
\end{abstract}




\section{INTRODUCIÓN}

O presente traballo pretende facer unha breve revisión dos aspectos teóricos e ideolóxicos explicitados por Teresa Moure nas súas obras: A palabra das fillas de Eva (2005) e Queer-emos un mundo novo (2012), mostrando a evolución das súas ideas e analizando as contradicións que se dan nos propios textos da autora. Será interesante analizalas nunha das súas obras máis importantes e coñecidas, Herba Moura (2005), novela na que se dá voz a tres mulleres, rescatándoas do segundo plano onde foron colocadas pola historia.

A palabra das mulleres, a sabedoría popular feminina, a maternidade ou a sexualidade xogarán un papel moi importante tanto nos ensaios como na produción novelística da autora galega. O que se intentará reflectir nas seguintes páxinas é se os preceptos teóricos son os mesmos que aparecen na obra literaria, ademais de argumentar que a autora galega tende a posicionarse, nas obras seleccionadas, do lado do feminismo da diferenza, se ben a evolución de ideas cara á teoría queer queda patente na obra Queer-emos un mundo novo. Tamén intentará establecerse como son presentadas as tres mulleres protagonistas de Herba Moura, sobre todo en relación cos personaxes masculinos (queda xa patente que nesta obra a autora traballa co binomio home/muller) para así amosar as reivindicacións feministas que se traslocen nos seus textos.

2. O FEMINISMO DA DIFERENZA E A IDENTIDADE FEMININA: $A$ PALABRA DAS FILLAS DE EVA E HERBA MOURA

Se o xénero non é entendido tan só en relación á bioloxía, se non que se entende como unha construción social: podemos falar realmente da existencia dunha identidade feminina? Aquí tentaremos responder a esta pregunta desde a perspectiva que amosa Teresa Moure no seu ensaio A palabra das fillas de Eva, texto no que a autora desenvolve as súas ideas no marco das teorías do feminismo da diferenza, un movemento ideolóxico de corte esencialista que xurdiu nos anos 70:

Según el exhaustivo e influyente análisis de Echols, el feminismo radical estadounidense habría evolucionado hacia un nuevo tipo de feminismo para el que utiliza el nombre de feminismo cultural. La evolución radica en el paso de una concepción constructivista del género, a una concepción esencialista. Pero la diferencia fundamental está en que mientras el feminismo radical -y también el feminismo socialista y el liberal- lucha por la superación de los géneros, el feminismo cultural parece afianzarse en la diferencia. En Europa, especialmente en Francia e Italia, también han surgido (...) feminismos que se autoproclaman defensores de la diferencia sexual. De ahí su designación como feminismos de la diferencia frente a los igualitarios. (De Miguel 2007)

O feminismo da diferenza francés intentaba buscar a esencia das mulleres e así diferencialas do home, polo que seguindo esta liña de pensamento si poderiamos dicir que existe una identidade feminina diferente á masculina e, ademais, que esta se reflicte na literatura, que é a que a nós nos concerne. A muller é considerada o Outro: "Instalado en dicha otredad, pero tomando prestada la herramienta del psicoanálisis, utiliza la exploración del inconsciente como medio privilegiado de reconstrucción de una identidad propia, exclusivamente femenina" (De Miguel 2007). A muller non forma parte activa da sociedade, representa unha ameaza para o sistema patriarcal imposto, e por iso é deixada nun segundo plano: sumisas, en casa, caladas, durmidas. Esta teoría trata, polo tanto, de buscar unha identidade propia femenina, de liberar as mulleres do xugo falocéntrico, que as converte en meros obxetos, sen perder a súa esencia do ser muller. Entre as representantes deste movemento destacan Annie Leclerc, Hélène Cixous e Luce Irigaray. Unha das claves da análise de Hélène Cixous radica no que ela denomina o "pensamento binario machista":

El pensamiento siempre ha funcionado por oposición (...) Por oposiciones duales, jerarquizadas. Superior/Inferior (...) La jerarquización somete toda la organización conceptual al hombre. Privilegio masculino, que se distingue en la oposición que sostiene, entre la actividad y la pasividad. Tradicionalmente, se habla de la cuestión de la diferencia sexual acoplándola a la oposición: actividad/pasividad. (...) en la filosofía la mujer siempre está del lado de la pasividad. (1995: 14-15) 
A isto Cixous contrapón "la diferencia múltiple y heterogénea" (Moi 1988: 115), idea que parte do concepto da différance de Jaques Derrida, e que será determinante para a súa teoría sobre a escritura feminina, que desenvolve no seu ensaio Le Rire de la Méduse. A autora intenta romper co binarismo falocéntrico imposto socialmente e crear un tipo de escritura máis libre, que penetre no Outro, e que atenda á diversidade:

Diré: hoy la escritura es de las mujeres. No es una provocación, significa que: la mujer acepta lo del otro. No ha eliminado en su convertirse en mujer, la bisexualidad latente en el niño y la niña. (...) Al hombre le resulta mucho más difícil dejarse atravesar por el otro. La escritura es, en mi, el paso, entrada, salida, estancia, del otro que soy y no soy, que no sé ser, pero que siento pasar, que me hace vivir -que me destroza, me inquieta, me altera, ¿quién?-, ¿una, uno, unas?, varios, del desconocido que me despierta precisamente las ganas de conocer a partir de las que toda la vida se eleva. (Cixous 1995: 46)

Teresa Moure, na súa obra $A$ palabra das fillas de Eva, segue a liña destas ideas e afirma a existencia dunha literatura feminina, ademais de soster a existencia dunha linguaxe masculina e doutra feminina: "[o discurso das mulleres] é un discurso irrelevante, lixeiro, discurso de conversa, de leira, de relato oral, pura rexouba. $\mathrm{O}$ discurso masculino, en cambio, é un discurso elevado, por veces científico, rigoroso" (2005a: 22-23). Moure, nalgunhas das súas obras, explota estes tópicos sobre a linguaxe e apodérase das características propias das mulleres, que están en contacto coas tradicións orais, que falan, que transmiten tenrura, etc. reivindicando así a idea do ser muller, transportándonos a través das verbas a un mundo no que as mulleres se queren como son, sen complexos, reivindican o seu corpo, a súa independencia e a súa identidade feminina. Na súa novela Herba Moura estas ideas están plasmadas moi claramente en certas personaxes, por exemplo, en Hélène Jans: "É unha muller, non cabe dúbida. E, no entanto, está a ler. E non relatos de amores nin versos procaces, que le unha obra médica. Algo malo quererá aprender lendo un libro" (Moure 2005b: 116). Hélène é unha personaxe que caracteriza as mulleres que consideran a súa independencia como un dos seus máximos valores. Ela non quere ser máis a filla dun boticario, nin a criada dun libreiro, nin a amante dun filósofo (Descartes), senón que quere ser ela mesma, escribir por si mesma; en definitiva, ser Hèléne Jans. Esta reafirmación da identidade femenina personificada en Hélène Jans, e non en ningunha outra persoa, é un dos matices máis importantes da personaxe, e aínda se pode interpretar como unha forma de entender a vida e o mundo: temos que afirmarnos como o que somos e non como o que os outros (o patriarcado) queren que sexamos. A autora busca empoderar as súas personaxes mais sen perder a esencia feminina. Para a análise da pegada das ideas teóricas de Teresa Moure na súa literatura que aquí estamos a realizar, consideramos importante traballar co dualismo home/ muller, entendendo o primeiro como representación das estruturas patriarcais en xeral, e a muller como parte dun deses grupos sociais esquecidos e oprimidos polo patriarcado. Esta tese, reflectida na obra literaria, é tamén una idea defendida pola propia autora:

$\mathrm{Na}$ sociedade había uns valores que eran tradicionalmente de homes e outros tradicionalmente de mulleres. Iso son roles, unha asignación convencional que di que os rapaces son guerreiros e as rapazas choronas. Chega un momento no que o feminismo di: non, queremos deixar de ser choronas, queremos ser todos iguais. Isto foi moi importante, pero o resultado social dese proceso non está sendo moi bo. As mulleres sobrecárganse de tarefas para ser tan tíos coma os tíos, pero non sempre os homes mudan algo ou mudan moi pouco. As mulleres teñen que ser excelentes amantes, excelentes chicas, excelentes mamás se corresponde, excelentes profesionais, estar sempre perfectas. Iso crea unha serie de tensións nas mulleres moi fortes. O modelo da igualdade non é o todo do feminismo. Hai versións que aparentan máis conservadoras pero en realidade son máis radicais: "non, espera, ti mira quen queres ser". Ese modelo de feminismo iría dirixido tanto aos homes como ás mulleres. (Cid 2007)

Ás veces pénsase que a igualdade consiste en vivir como os homes, polo que moitas mulleres se incorporan a postos de prestixio, introdúcense en ambientes académicos e aceptan traballos 
nunca antes feitos por mulleres (cfr. Moure 2005a: 80). Porén, esta subversión dos traballos "prohibidos" converteuse ao final nunha forma de acceso da muller ao sistema capitalista, e polo tanto a muller comezou a formar parte da engranaxe produtiva, na que segue estando considerada por debaixo dos homes. Estas ideas críticas, sempre cun matiz reivindicativo, amósaas Teresa Moure tanto en Christina de Suecia como en Hélène Jans. A primeira, muller erudita, que sendo raíña de Suecia gastaba todo o orzamento en libros e en levar sabios á súa corte, termina abdicando do trono, para buscarse a si mesma.

\subsection{SABEDORÍA FEMININA: A PALABRA DAS MULLERES}

Se o feminismo da diferenza recoñece unha identidade feminina propia, como xa se argumentou, tamén reivindica unha linguaxe propia:

Varones y mujeres aprenden sus estilos de conversación en grupos de pares del mismo sexo. Desde este punto de vista, se crían en diferentes medios culturales, de modo que también desarrollan distintos hábitos para señalar sus intenciones y sus comprensiones. Puesto que aprenden a mantener conversaciones en interacción con sus pares del mismo sexo, las mujeres y los hombres desarrollan normas diferentes para establecer y exhibir implicación conversacional. Estas diferencias "culturales" explican los modelos diferentes que se observan entre niñas y niños y mujeres y hombres, así como las evaluaciones mutuamente negativas que a menudo resultan de las interacciones intergenéricas. (Tannen 1996: 96)

Esta idea reflíctese, na nosa opinión, en Herba Moura, por exemplo no momento en que as mulleres se xuntan en torno á parturiente e intercambian consellos, anécdotas, etc. Ademais, Teresa Moure, no seu ensaio $A$ palabra..., apoia a tese de que as mulleres teñen unha forma de falar propia:

Ser home ou muller é un accidente biolóxico, así que todos, feitos da mesma lama, podemos acceder ás mesmas habilidades, ás mesmas virtudes, aos mesmos defectos. A sociedade constrúenos logo como mulleres ou como homes a través de poderosos mecanismos de modelización, do estilo da linguaxe que estamos sometendo a análise. A proposta que se fai nestas páxinas é unha invitación a valorar a palabra, sempre acalada, da muller; non porque as mulleres teñan máis razón cós homes, non porque sexan mellores. (Moure 2005a: 115116)

A reflexión sobre a existencia dunha linguaxe propia feminina non fica só ancorada nos ensaios da escritora galega, senón que vai quedar reflectida aínda tamén nas súas novelas. Consideramos imprescindible mencionar a importancia da linguaxe en Herba Moura, sobre todo a través da figura de Hélène Jans, á que se atribúe o idear unha proposta para a creación dunha linguaxe universal, algo que Einés Andrade considerará que influíu nas ideas de Descartes. Esta formulación literaria é unha forma de reivindicación da muller, sempre excluída do discurso intelectual, establecido só para os homes. Porén, Hélène decide non dar a coñecer a súas ideas ao respecto, e así non introducirse nun mundo de masculinidades ególatras. Ela prefire céntrase na súa propia linguaxe e concentrar os seus esforzos na transmisión do saber popular e do seu propio coñecemento de remedios naturais. Consideramos que esta é a súa propia linguaxe, coa que, a través do seu Herbario, intenta achegarse a todas as demais mulleres. No entanto, é unha linguaxe non permitida, por subversiva, por se opor aos estándares de cultura impostos. Hélène será acusada de practicar a bruxería e mandarana matar, polo feito de se rebelar contra o discurso socio-patriarcal imposto.

Deste xeito, a linguaxe non é só unha cuestión teórica, senón que tamén será importante en canto ao papel que xoga como forma de comunicación entre as mulleres e como ferramenta de transmisión da sabedoría popular feminina. Hélène Jans é a personaxe que representa o mundo da sabedoría tradicional, sempre en mans femininas, xa que reflicte o saber das curandeiras, das parteiras...; o seu oficio é o de meiga:

Teresa Moure nos plantea otras formas de saber alternativas y nos introduce en el universo femenino de la mano de Hélène, una mujer que, precisamente, pertenece a uno de los colectivos femeninos más castigados en su 
tiempo: las sanadoras y "brujas". Consideradas peligrosas debido a una sabiduría que escapaba de los cánones tradicionales, estas mujeres fueron menospreciadas y perseguidas por una sociedad dominada por hombres que veían en ellas a seres inteligentes e independientes capaces de desestabilizar el mundo y las normas que ellos mismos habían forjado. La novela dignifica la figura de la bruja mostrándonos el espíritu de nuestra protagonista, una mujer sabia y luchadora que intenta aprovechar al máximo los elementos que la naturaleza pone a su disposición. (Mesas Gómez 2007)

Hélène relata como no momento do parto as mulleres se reunían arredor da cama da parturiente a falar, sobre todo das súas experiencias como nais, dos seus partos, dando consellos ás primeirizas, etc. (cfr. 2005b: 137); con esta práctica as mulleres creaban un espazo propio no que partillaren a súa sabedoría popular: “(...) as mulleres antes vivían en un gueto, e nese gueto desenvolvían valores. É certo que as mulleres só desenvolvían traballos domésticos, pero tamén é certo que algúns valores eran alternativos aos da cultura masculina, a do mercado, a competitiva..." (Cid 2007). Esta sabedoría popular, de mulleres, será posteriormente medicalizada e masculinizada, pois a medicina e as empresas farmacéuticas, entidades, nun principio do patriarcado, serán as que se fagan cargo dos partos, e as parteiras e curandeiras serán relegadas ao esquecemento. Porén, Teresa Moure achega unha nota de esperanza na súa obra, pois o saber de Hélène Jans traspasa as fronteiras do tempo a través do seu Herbario, que chegará ás mans de Einés Andrade, unha rapaza do século XX. Con iso, a autora incita os lectores a voltar a esa sabedoiría popular, a natureza, e deixar de lado o capitalismo que nos afoga cada día máis. No Herbario de Hélène encontramos escritos moitos remedios caseiros, todos naturais, baseados na utilización das plantas medicinais, sobre todo usados para calmar as dores durante a menstruación, o parto, etc.; é dicir, un saber de mulleres para mulleres, facendo así a Hélène dona da tradición popular, que no século XVII aínda estaba en mans femininas. Vemos, polo tanto, como a autora idealiza o saber das mulleres, remarcando de novo, a existencia dunha identidade propiamente feminina.
Hélène recollerá esta sabedoría feminina no seu Herbario; a palabra é unha das armas que teñen as mulleres, sempre relegadas ao silencio, para loitar contra o patriarcado: “A palabra das mulleres debe atenderse porque compón unha testemuña obvia dunha cultura minorizada, desprestixiada, que non conta" (Moure 2005a: 113). Einés Andrade, en Herba Moura, será a personaxe que, a través da súa propia voz e da súa propia historia, recupere as figuras de Hélène e de Christina de Suecia. Nacida nunha casa na que só coexisten mulleres reafirmará na obra as súas propias ideas sobre a liberdade e a emancipación femininas. O momento da vida de Einés que a autora nos mostra é o momento da escrita da súa tese doutoral, que versa sobre Descartes; mais, sabendo que é case imposible achegar nada novidoso aos estudos xa feitos sobre o filósofo, decide mudar o concepto do seu traballo e centrarse na historia das dúas mulleres máis importantes da vida deste: Christina de Suecia e Hélène Jans. O relato de Einés estará baseado na tradición, nos supostos papeis atopados no faiado da súa casa, entre os que se encontran cartas entre Hélène e Christina, follas do Herbario de Hélène, etc. Esta perspectiva da historia, e da vida do filósofo, a que Einés constrúe, é unha vida na que as mulleres cobran relevancia e son reivindicadas, xa que non só son presentadas como simples "anexos informativos" da vida de Descartes, se non que son unha fonte importantísima de influencia nas ideas e na vida do filósofo. Mais esta perspectiva que Einés quere fornecer aos estudos sobre Descartes non é apoiada polo seu director de tese, un importante profesor de universidade de filosofía que, ancorado no discurso científico masculino, é incapaz de comprender as ideas que a rapaza lle presenta.

As protagonistas de Herba Moura deixan de estar nun segundo plano, a autora galega rompe coa popular frase "detrás de todo gran home sempre hai unha gran muller", e sitúa en primeira plana da historia as súas personaxes. Elas tamén son as que fan que o mundo xire, as que inventan, as que escriben, as que crean, as que curan. Así o explica a propia Teresa Moure nunha entrevista: 
(...) lo que yo pretendía era escribir una historia de las mujeres desde un punto de vista alternativo al de la versión oficial que nos contaron, donde como estaban recluidas en sus casas y alejadas del dominio público, simplemente no existían. De hecho, en la novela el nombre de Descartes tarda casi cien páginas en aparecer y es aludido como "el filósofo", porque la obra no trata de las mujeres de Descartes, sino de las mujeres en la época de los descubrimientos. (Hernández 2010)

As ideas da autora galega percorren a súa literatura, na que adopta un discurso feminino literario que rompe coas estruturas do masculino, o preponderante, o imposto; é dicir, crea una literatura radical e feminista coa que "recorrer ás experiencias humildes das mulleres, ás insignificantes experiencias femininas que constitúen o derradeiro tabú da nosa cultura precisamente por non ter entrado na literatura" (Moure 2005a: 30).

Segundo o exposto anteriormente, tanto no ensaio A palabra... como na obra Herba Mou$r a$, as ideas de Teresa Moure tenden cara ao feminismo da diferenza: quere sacar a muller do esquecemento, presentala como suxeito activo da sociedade, onde xa non cumpre máis que co papel de muller e esposa, mais en ningún momento se cuestiona a feminidade, senón que se intenta intensificala. Polo tanto, podemos afirmar que nos textos mencionados a autora galega si diferencia entre una identidade masculina e feminina.

\subsection{MATERNIDADE E SEXUALIDADE EN TERESA MOURE}

O feminismo da diferenza, e con isto, moitas das súas representantes como Kristeva, Irigaray ou Cixous, entenden que as mulleres deben reapropiarse da maternidade: "Esta perspectiva feminista convierte la maternidad en sinónimo de un vínculo intrínseco y básico entre las mujeres; contempla con un nuevo enfoque las relaciones materno-filiales y, al mismo tiempo, rechaza la «institución materna»" (Saletti Cuesta 2008:178). Adrienne Rich no seu libro Of Woman Born, fala deste duplo sentido que ten a maternidade na nosa sociedade:
I try to distinguish between two meanings of motherhood, one superimposed on the other: the potential relationship of any woman to her powers of reproduction and to children; and the institutions, which aims at ensuring that that potential -and all women- shall remain under male control. (Rich 1995: 13)

Neste sentido, Teresa Moure coincide coas ideas aquí expostas, e así o afirma en $A p a-$ labra... Se ben a muller pode ser nai, e polo tanto reivindicar a maternidade como algo seu, tamén hai que apuntar que ser muller non ten que implicar obrigadamente o ser nai, xa que isto implicaría perpetuar a "institución da maternidade":

Podería deducirse, (...) que a aventura da maternidade é a única que se vai reclamar como peculiar da muller. Nada máis lonxe da realidade. Muller e nai non son categorías idénticas e converter a maternidade no proxecto co que as mulleres acadan unha existencia 'completa' é un dos máis fortes mitos da nosa cultura, mito recente e burgués onde os haxa. (2005a: 29-30)

Esta concepción da maternidade, reflectida na obra Herba Moura na personaxe de Christina, é inadmisible socialmente, pois é unha forma subversiva de cambiar a realidade, é dicir, unha forma de por en discusión a estrutura social creada. Ademais, hai que ter en conta que, se aceptamos este papel reprodutor que se nos concede, temos que marxinar socialmente non só a todas as mulleres que non queren ser nais, se non, a todas aquelas mulleres que por moi diferentes razóns non poden ter fillos:

A maternidade é unha construción social, non é algo biolóxico. Hai moitas persoas que son nais independentemente de non ser mulleres, ou de non pariren nunca. Hai moitas mulleres que pariron e non son nais, aínda que exerzan socialmente como nais. É un tipo de construción independente. (Cid 2007)

Christina de Suecia é a personaxe que exemplifica esta idea en Herba Moura, pois, presionada para casar e dar herdeiros ao seu pobo, deixa o trono, para non se converter en escrava do mesmo, polo que a súa "fuxida" é máis ben un paso cara á liberdade, un paso para achegarse a ela mesma e así atopar a súa propia identidade. Nesta obra a autora 
galega dá voz e protagonismo a dúas mulleres que foron esquecidas pola historia, unha obra na que se amosan moitas das ideas expresadas nos dous ensaios aquí mencionados. A palabra das fillas de Eva comeza co relato dunha muller sobre a experiencia do parto; con isto Moure constrúe unha nova forma de entender a literatura, neste caso, desde o punto de vista da muller embarazada, co que achega outra visión da maternidade, que ás veces non é tan marabillosa como se nos fai crer. O parto é dor, é anguria e sobre todo é unha mestura de sentimentos encontrados. A muller é considerada, desde hai moitos anos, como un obxecto que tan só serve para a reprodución da especie; así foi como a maternidade foi roubada das mans das mulleres, como se masculinizou, polo que Moure avoga por unha volta á natureza, ao mundo animal, defendendo o feito de aleitar as crías, como forma de loita contra a sociedade industrial e do consumismo:

Sempre me identifiquei com o ecofeminismo; é normal que veja uma forte semelhança entre as duas correntes, que se calhar não se vê tanto noutras posições feministas. Estes pensamentos põem o foco nas estruturas de domínio que ficaram fora do pensamento hegemónico ocidental, num caso para subjugar a natureza, noutro as mulheres. O modelo é, porém, o mesmo: o homem como dominador da natureza. Uma concepção hierárquica que subordina a natureza e as mulheres. E esta é uma questão fundamental para elaborar qualquer resposta contrapoder. (Dopico 2014)

En Herba Moura nárrase o nacemento de Einés Andrade, da que se nos conta que ao saír de entre as pernas da súa nai, se escorreu ao chan onde a gata da veciña a lambeu enteiriña, como se da súa propia filla se tratara. O relato do nacemento de Einés é tamén importante, porque, como a propia Moure, nace mentres o home chega á lúa. E é o home quen chega alí, non é a humanidade, ou o home entendido como xenérico, no que tamén deberían sentirse incluídas as mulleres, que, no entanto, non o fan. Este nacemento rodeado de mulleres, pero "supervisado" por un home, Amstrong, que responde á representación do home xenérico, como fin último do patriarcado, conseguirá que Einés intente rebelarse contra esa supervisión externa, e quererá atoparse a si mesma. Rebelarase contra a opinión do seu director de tese, que lle intenta cortar as ansias de liberdade, e terá como referente a dúas mulleres que se afirman, xa non só como mulleres, senón como suxeitos independentes: Christina de Suecia e Hélène Jans, ás que consegue, a través da súa propia historia, tirar do seu inmerecido esquecemento.

Christina é presentada como unha muller que vive por e para o coñecemento, algo que estaba mal visto tanto no século XVII como hoxe en día, xa que non representa a imaxe da nai-natural, e dicir, a que é nai e esposa, senón todo o contrario, é unha muller sabia que non quere ser nai: "Christina está arrepiada. Porque queren obrigala a ser dun home, ela, ser unha posesión; ser ventre para producir xermolos. (...) Ela non quere ser nai e pensa que por algo ela é rara, abondosa en amantes e pouco comedida (...)" (Moure 2005b: 31). A propia personaxe séntese excluída da "normalidade", do feito de que as mulleres teñen que ser nais; séntese rara... pero qué é realmente ser raro? Non adoptar as normas impostas? A sociedade patriarcal fai que unha muller que non queira ter fillos quede excluída do seu universo de valores, é dicir, da súa "normalidade".

A reivindicación da maternidade como algo que a muller pode escoller tamén é unha forma de recuperar o corpo da muller para as mulleres e deste xeito tamén a súa sexualidade, que debe deixar de encaixar na norma patriarcal establecida, e así poder alcanzar a liberdade. En Herba Moura, Christina de Suecia está, neste sentido, tamén fora das marxes da "normalidade" imposta:

"Válenlle igual mancebos que raparigas" e gargallada que racha o aire. E a opinión non é xusta, que non é cuestión do que lle vale ou non lle vale, senón, máis ben, do que lle gusta e o que non. A este respecto habería moito que puntualizar, que non lle gustan igual uns e outras, que lle gustan distinto. Como tamén lle gustan distinto uns ca outros, e algunhas ca outras. (Moure 2005b: 26)

A sexualidade da raíña tamén está mal vista pola sociedade, por non adecuarse á norma, en tanto que a muller ten que relacionarse 
sexualmente co home tan só para reproducirse (que non ao revés, xa que o desexo masculino si está ben visto). A través desta personaxe a autora reivindica todas aquelas sexualidades que se esquecen baixo a moral puritana social. Christina representa o desexo sexual; non é mesurada, non é un simple obxecto reprodutivo, se non que goza do sexo, é luxuriosa, e iso é unha forma radical de se erguer contra as constricións sociais que se impoñen ás mulleres. Ela goza do seu corpo, e dos corpos alleos, recupera algo que nos foi roubado: a nosa propia intimidade, o desexo sexual, o noso corpo.

\section{UNHA BREVE OLLADA A QUEER- EMOS UN MUNDO NOVO}

Será na obra Queer-emos un mundo novo, onde a Teresa Moure desenvolva estas novas ideas que rompen totalmente co concepto tradicional de identidade e co binarismo home/ muller:

Basicamente a teoría queer atrévese a formular que todas as personas somos dabondo raras como para nos axustarmos a categoría ningunha, que nin o xénero -como suposto social- nin o propio sexo- como base biolóxica do xéneroexisten, que son puras construcións inoculadas pola cultura e o contorno social. (2012: 33)

Neste ensaio atopamos a asunción da teoría queer por parte de Moure, que afirma que a identidade está totalmente desnaturalizada, que non existen os xéneros, e polo tanto non existe a dualidade masculino-feminino, teoría defendida cada vez máis pola autora galega, como ben se amosa nunha entrevista recente:

E isso é muito libertador para os indivíduos. Mas, logicamente, ao romper o género, deixa de haver um nós. Os feminismos reagem lembrando que foi o pensamento feminista o primeiro em questionar o género. Mas queer vai além disso. Porque considera que também não há sexo, que o sexo é uma construção. Eis onde queer o feminismo, digamos clássico, podem ver-se dissociados. O feminismo diz que as mulheres ainda não atingimos uma igualdade real, como para prescindirmos desse nós forte. E é verdade. É um debate interessante. Mas para mim queer é mais evocador. Eu não posso estabelecer laços de solidariedade com uma pessoa com a que não tenho muito a ver só por ter os mesmos genitais, e ao mesmo tempo distanciar-me de alguém com quem tenho uma relação mais íntima porque o seu corpo não é como o meu. Pode haver homens feministas e mulheres não feministas. Com efeito, o feminismo clássico corresponde com um momento histórico que ainda precisamos, mas acho que o objectivo é rachar com os géneros. (Dopico 2014)

A identidade feminina oposta á masculina, como forma dun binomio, non existe, xa que "transitamos entre tantas identidades de xénero como sexamos capaces de crear ao longo da existencia" (Moure 2012: 65). Así pois, estas ideas, que contrastan co visto ata agora, serán reflectidas nalgunhas das súas derradeiras obras como en Benquerida Catástrofe (2007), novela que a propia Moure considera como un exemplo de literatura queer en galego. Esta obra pretende dar vida a un personaxe subversivo, o de Adam, que se transexualiza, amosando así a loita de todos aqueles que se senten engaiolados nun corpo que non lles pertence, e que loitan por cambiar a súa identidade, unha identidade imposta pola estrutura social patriarcal, que, como é ben sabido, é heterosexual, branca e masculina. Adam feminízase e a súa percepción do mundo tamén o fai. A autora amosa a loita persoal deste personaxe, que é unha loita interna, e tamén externa, contra os clixés sociais. A culminación da transformación de Adam é o encontro do amor verdadeiro en Marisa, a quen lle é completamente indiferente "a envoltura" física de Adam. Con esta obra Moure presenta a súa percepción da realidade e as súas ideas sobre a identidade, na liña da teoría queer. Benquerida Catástrofe, é unha forma de crítica social contra as identidades impostas por unha sociedade que non busca máis que o beneficio propio, e tamén é o triunfo de todos aqueles que loitan por conseguir ser quen queren ser:

[Benquerida catástrofe é] un texto co que pretendo animar aos lectores e lectoras a preguntarse pola súa identidade sexual, porque en literatura o tema da orientación sexual é relativamente frecuente, pero o da identidade non o é tanto. Quería provocar en quen me lea o afán de buscar o transexual que todos levamos dentro, ese outro sexo que sempre está aí e que ás veces se materializa máis cando estabelecemos relacións amorosas cunha nova persoa. O proxecto inspírase en determinadas 
correntes filosóficas, como Judith Butler e o pensamento queer, e nesa fermosa idea de que todas somos raras e de que, fronte á obriga de vivir consonte os roles de muller ou de home, pode haber tantas identidades sexuais como individuos. (Vilavedra 2007)

Se as identidades pechadas non existen como tal, se consideramos importante sacar do seu inmerecido esquecemento as voces de todos os grupos sociais que non encaixan nas estruturas de poder, que son considerados subversivos e aos que se lles negou a voz, condenándoos ao silencio. Porén, nalgúns puntos deste ensaio parecen agromar as ideas expostas, anos antes, na obra $A$ palabra... Teresa Moure afirma en Queer-emos... que: "Os homes exercen unha relación de poder sobre as mulleres derivada de que estas son as que xestan e paren. Os homes están desprovistos pola natureza desde poder e compénsano inventando mitos sobre a falta de forza física das mulleres (...)" (2012: 17). Esta idea fai que moitas mulleres

procurasen desvincularse dos roles culturalmente asociados ao seu sexo e traballasen contra o sexismo, sometendo a unha escrupulosa investigación practicamente todas as dimensión das súas existencias: a maternidade, desde logo, mais tamén cuestións como a que dedicarse, como amar, a quen amar ou como facelo (Moure 2012: 17-18).

Como se observa, a autora volve dividir a sociedade en "homes" e "mulleres". Máis adiante, nesta mesma obra, a autora tratará o concepto de literatura feminina, que "será feminina na medida en que responda a noción de muller política, non á de muller biolóxica. Neste sentido, "devir-muller" non é nacer con corpo de muller, nin travestirse de tal, senón poñerse na pel de quen sofre opresión de xénero" (Moure 2012: 28). Aquí volve reivindicar a identidade feminina, achegándose de novo aos preceptos do feminismo da diferenza.
Concluímos que se ben as reflexións de Teresa Moure no ensaio Queer-emos... intentan achegarse máis ás teorías feministas da terceira vaga, aínda queda un pouso das ideas do feminismo da diferenza explicitadas no seu anterior escrito A palabra... No entanto, consideramos que Teresa Moure vira cada vez máis cara a estas ideas queer.

\section{CONCLUSIÓNS}

Teresa Moure proclama nas súas obras literarias a liberdade do individuo, e concretamente na súa obra Herba Moura a reivindicación céntrase en dotar de voz as mulleres esquecidas da historia. Ningunha das protagonistas encaixa, per se, na concepción tradicional de muller, cada unha delas buscará a súa propia identidade para se construír como suxeitos ceibes. Porén, os homes parecen estar máis estereotipados, recalcando así as súas características negativas, que se contrapoñen aínda con máis forza ás positivas que encarnan as personaxes femininas. Como se expuso neste pequeno traballo, as ideas da autora galega, tanto en A palabra..., en Herba Moura e, nalgúns casos, nas ideas expostas en Queeremos... achéganse de forma bastante clara aos conceptos asumidos polo feminismo da diferenza. Moure xoga co binarismo entre home/ muller, se ben quere que estas últimas escapen ás imposicións heteropatriarcais.

Por todo isto, consideramos que as obras de Teresa Moure, tanto os ensaios como as novelas, son escritos reivindicativos, que intentan salvar do esquecemento a todas aquelas e aqueles que a sociedade relega a un segundo plano só polo feito de non ser parte da súa "normalidade". Coas súas obras apoiamos a tese de que a literatura, como crítica social, nos serve como forma de rebelión e de emancipación.

\section{REFERENCIAS BIBLIOGRÁFICAS}

Basanta Valles, Noemi (2012): Reseña de Queer-emos un mundo novo, Cadernos de Lingua 34, pp. 195-200.

CAminada Rosseti, Lucía (2010): "Literatura gallega e identidad femenina. La propuesta de Teresa Moure", en M. González de Sande (ed.), La imagen de la mujer y su proyección en la literatura, la sociedad y la historia. Sevilla: ArCiBel Editores, pp. 67-78. 
CID, Xavier (2007): “A tenrura é un valor profundamente revolucionario. Entrevista a Teresa Moure", Suplemento ProTexta de Tempos Novos 123 (22/09/2007) (dispoñíbel en: http:// www.aelg.org/Centrodoc/GetParatextsByAuthor.do?authorId=autor284).

Cixous, Hélène (1995): La risa de la medusa. Barcelona: Anthropos.

De Miguel, Ana (2007): “Los feminismos a través de la historia” (dispoñíbel en: www.mujeresenred.net).

Dopico, Montse (2014): “O amor de mãe tópico tem uma leitura antipolítica. Entrevisa a Teresa Moure", Praza Galicia 13/10/2014 (dispoñíbel en: http://praza.gal/cultura/7994/lo-amor-demae-topico-tem-uma-leitura-antipoliticar/).

HERnÁNDEZ, Susana (2010): “Entrevista a Teresa Moure”, Libros y literatura 14/06/2010 (dispoñíbel en: http://www.librosyliteratura.es/entrevista-a-teresa-moure.html).

Mesas Gómez, Lidia (2007): Reseña de Herba Moura, Lletra de Dona (dispoñíbel en: http:// www.ub.edu/cdona/lletradedona/herba-moura).

MiguÉLEz CARBAlleira, Helena (2006): “Inagurar, reanudar, renovar. A escrita de Teresa Moure no contexto da narrativa feminista contemporánea", Anuario de estudos literarios Galegos 2006, pp. 72-87.

Mills, Sara e Louise Mullany (2011): Language, Gender and Feminism: Theory, Methodology and Practice. Nova York: Routledge.

MoI, Toril (1988): Teoría literaria feminista. Madrid: Cátedra.

Moure, Teresa (2005a): A palabra das fillas de Eva. Vigo: Galaxia.

(2005b): Herba moura. Vigo: Xerais

(2007): Benquerida catástrofe. Vigo: Xerais.

(2012): Queer-emos un mundo novo. Vigo: Galaxia.

Rich, Adrienne C. (1995): Of Woman Born: Motherhood as Experience and Institution. New York: W. W. Norton.

Saletti Cuesta, Lorena (2008): "Propuestas teóricas feministas en relación al concepto de maternidad", Clepsydra 7, pp. 169-183.

TANnen, Deborah (1996): Género y discurso. Barcelona: Paidós.

Vilavedra, Dolores (2005): Reseña de Herba Moura, Lectora 11, pp. 331-333.

(2007): "Non hai historias, hai xéneros. Entrevista a Teresa Moure", El País (edición Galicia) 16/03/2007 (dispoñíbel en: http://elpais.com/diario/2007/03/16/galicia/1174043911 850215.html). 